\title{
O uso de indicadores ambientais na avaliação de unidades de conservação: o caso do Parque Estadual do Utinga em Belém/PA
}

(PEUT)

O Parque Estadual do Utinga (PEUt) está inserido na Região Metropolitana de Belém (RMB), criado em 1993, o objetivo principal foi assegurar a vida útil dos lagos Bolonha e Água Preta responsáveis pelo abastecimento de água potável da capital. Nesse sentido, a construção de um sistema de indicadores ambientais para analisar a efetividade da gestão ambiental do parque urbano tornou-se uma ferramenta fundamental na compreensão das vulnerabilidades ambientais, identificando os impactos das ações humanas da Unidade de Conservação de proteção integral.

Palavras-chave: Parque Urbano; Sistema de Indicadores; Vulnerabilidade Ambiental.

\section{The use of environmental indicators in the evaluation of conservation units: the case of the Utinga State Park in Belém/PA (PEUT)}

The State Park of Utinga (PEUt) is part of the Metropolitan Region of Belém (RMB), created in 1993, the main objective was to ensure the life of the Lakes Bologn and Água Preta responsible for supplying drinking water to the capital. In this sense, the construction of a system of environmental indicators to analyze the effectiveness of the environmental management of the urban park has become a fundamental tool in the understanding of environmental vulnerabilities, identifying the impacts of the human actions of the Conservation Unit of integral protection.

Keywords: Urban Park; System Indicators; Environmental Vulnerabilities.

Topic: Gestão de Unidades de Conservação

Reviewed anonymously in the process of blind peer.
Received: 11/12/2019

Approved: 19/02/2020
Charles Benedito Gemaque Souza (iD Universidade Federal do Pará, Brasil http://lattes.cnpq.br/6419817700801648 http://orcid.org/0000-0002-5966-9556 gemaquec@ufpa.br

Amanda Souza Campos

Universidade Federal do Rio de Janeiro, Brasil http://lattes.cnpq.br/3749348327639606 http://orcid.org/0000-0002-0271-3739

amanda.campos@semas.pa.gov.br

Frank Bruno Baima de Sousa

Universidade Federal do Rio de Janeiro, Brasil

http://lattes.cnpq.br/7035171196848815

http://orcid.org/0000-0003-2548-0701

frank.sousa@semas.pa.gov.br

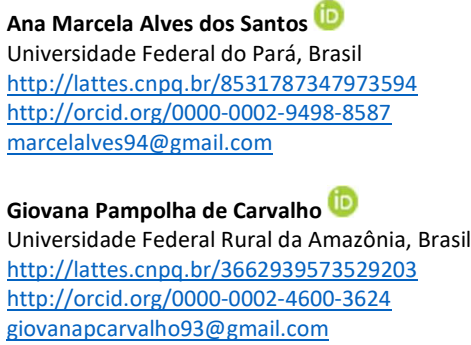

Referencing this:

SOUZA, C. B. G.; CAMPOS, A. S.; SOUSA, F. B. B.; SANTOS, A. M. A.; CARVALHO, G. P.. O uso de indicadores ambientais na avaliação de unidades de conservação: o caso do Parque Estadual do Utinga em Belém/PA (PEUT). Nature and Conservation, v.13, n.1, p.86-94, 2020. DOI: http://doi.org/10.6008/CBPC2318-2881.2020.001.0010 


\section{INTRODUÇÃO}

Os parques urbanos são áreas verdes legalmente instituídas com o objetivo de proteção integral, ou seja, a manutenção dos processos ecológicos, da diversidade genética e a utilização sustentada da natureza. Reconhece-se atualmente que a sua criação não se restringe apenas à preservação dos aspectos cênicos e paisagísticos, mas também da enorme riqueza filogenética e biológica que carregam os ecossistemas, além dos serviços ambientais prestados aos moradores.

Na prática, os parques urbanos na Amazônia, mesmo com todos os aspectos legais, ainda sofrem muitos problemas, tais como: territórios que não foram adequadamente demarcadas; exploração ilegal de recursos; ocupação irregular da área do entorno; dejeto de lixo, entre outras exposições antrópicas (DANA et al. 2016). Nesse sentido, demanda-se a compreensão dos fatores e processos que afetam o papel desta Unidade de Conservação de proteção integral, para serem melhor entendidos e dimensionados dentro do contexto de uma forma metropolitana.

No município de Belém, assim como muitas outras cidades brasileiras, não houve planejamento adequado, especialmente no que concerne o seu crescimento urbano e os impactos ambientais o que têm afetado direta e indiretamente a preservação da cidade. No caso do Parque Estadual do Utinga (PEUt), também tem a questão do espaço de recreação para os moradores, bem como possibilitar o desenvolvimento de atividades científicas, culturais, educativas e turísticas, acrescenta-se a questão da gestão dos mananciais que abastece a metrópole, que por sua vez depende da concretização dos objetivos alinhavados pelo SNUC.

Portanto, como método de investigação desse trabalho, propõe-se a avaliação de métodos de construção de um sistema de indicadores ambientais para analisar a efetividade da gestão ambiental do PEUt em três dimensões: social, político e ambiental. A adoção de indicadores envolve a perspectiva de ser utilizado no acompanhamento de cada fenômeno urbano/ambiental ao longo do tempo, no sentido de avaliar o progresso ou retrocesso em relação à preservação da área verde.

\section{MATERIAIS E MÉTODOS}

O termo indicador é oriundo do Latim 'indicare', que significa descobrir, apontar, anunciar, estimar. Van Bellen (2008) trata um indicador como uma medida que resume informações relevantes de um fenômeno particular ou um substituto desta medida, semelhante ao conceito de que um indicador é uma medida do comportamento do sistema em termos de atributos expressivos e perceptíveis.

Indicadores são medidas compostas de variáveis, ou seja, medições baseadas em mais de um dado. Van Bellen (2008) define variável como uma representação operacional de um atributo (qualidade, característica, propriedade) de um sistema. Os indicadores são variáveis e os dados são as reais medições ou observações. Embora os indicadores sejam apresentados na maioria das vezes em forma estatísticas ou gráficos, eles são distintos dos dados primários. Segundo o mesmo autor os indicadores e índices mais agregados estão no topo de uma pirâmide de informações cuja base são os dados primários derivados do 
monitoramento e da análise das medidas e observações.

Quando prevalece a dimensão ecológica, o Pressure, State, Response (PSR), tornam-se indicadores que assumem a existência de uma causalidade na interação dos diferentes elementos da metodologia, sendo que os indicadores da pressão ambiental (P) representam ou descrevem pressões da atividade humana sobre o meio, incluindo recursos; os de estado ou condição (E) se referem à qualidade do ambiente e a qualidade e à quantidade de recursos naturais; e os indicadores de resposta $(R)$ mostram a extensão e a intensidade das reações da sociedade em responder às mudanças e às preocupações ambientais.

Os Indicadores de Pressão estão caracterizados como qualquer ação antrópica que o ser humano traz ao meio ambiente e representam ou descrevem pressões das atividades humanas exercidas sobre o meio ambiente; tais pressões são também incidentes sobre os recursos naturais (COSTA, 2013). Tais indicadores estão diretamente ligados às ações que a sociedade vem realizando sobre o meio ambiente, que venham a comprometer os ecossistemas ambientais e são classificados em: diretos e indiretos. O primeiro diz respeito às ações que são influenciados diretamente pela ação antrópica como, por exemplo, o lixo produzido e contaminante de um modo geral tanto do ar, solo, água. Entretanto, as pressões aplicadas ao ambiente devido à forma como as ações humanas e atividades produtivas são realizadas é considerada como indireta.

Por fim, pode-se dizer que os indicadores de resposta social indicam as ações que a sociedade, gestores nas diversas esferas de governo vem realizando para mitigar a prevenção ou correção dos danos, impactantes por diversas formas de adaptação ou recuperação sobre o meio ambiente para que possa garantir um ambiente de qualidade, ou seja, promover a sustentabilidade.

Os indicadores de estado estão diretamente ligados a situação que o ambiente se encontra, ou seja, a qualidade dos ecossistemas hídricos (mananciais), solo, ar e vegetação. Os indicadores de estado ajudam na descrição e análise dos ecossistemas onde as cidades estão assentadas. É importante considerar a região de acordo com o ecossistema que está inserido e os elementos em questão, à medida que se observa a evolução do estado do meio ambiente local

Nesse contexto, as ideias de sustentabilidade das áreas verdes urbanas devem conciliar as três dimensões: equidade social, eficiência econômica e função ecológica, logo visto dentro do sistema complexo e ao mesmo tempo específico a realidade local (GARCIA et al., 2006). Além disso, no caso da avaliação da gestão ambiental do parque urbano existe o fator político-institucional que determina a capacidade adaptativa de resposta a exposição.

A construção do sistema de indicadores ambientais aqui proposto serão mecanismos que permitirão articular os objetivos da função ecológica do PEUT com as premissas das políticas públicas de sustentabilidade na cidade, em termos administrativos, sociais e territoriais. Desta forma, as informações selecionadas e as relações estabelecidas entre as variáveis de avaliação serão peças chaves para interpretação, a aplicação dos indicadores ambientais é considerada uma metodologia aplicada na avaliação da qualidade da gestão sendo fundamental que esses indicadores tenham os seguintes princípios básicos:

Comparabilidade: os indicadores devem permitir estabelecer comparações e apontar as mudanças ocorridas em termos de desempenho ambiental;

Equilíbrio: os indicadores ambientais devem distinguir entre áreas problemáticas (mau 
desempenho) e áreas com perspectivas (bom desempenho);

Continuidade: os indicadores devem assentar em critérios similares e em períodos ou unidades de tempo comparáveis;

Temporalidade: os indicadores devem ser atualizados com a regularidade necessária para permitir a adoção de medidas;

Clareza: os indicadores devem ser claros e inteligíveis.

Tomando como base a metodologia de criação e utilização de indicadores ambientais, conforme sintetizadas pelo Ministério do Meio Ambiente, bem como a estrutura conceitual do modelo de análise Pressão-Estado-Resposta (PER), originalmente proposto pela Organização para a Cooperação e Desenvolvimento Econômico (OCDE), com as premissas do Barómetro da sustentabilidade, a pesquisa no PEUt tem como matriz a seguinte configuração.

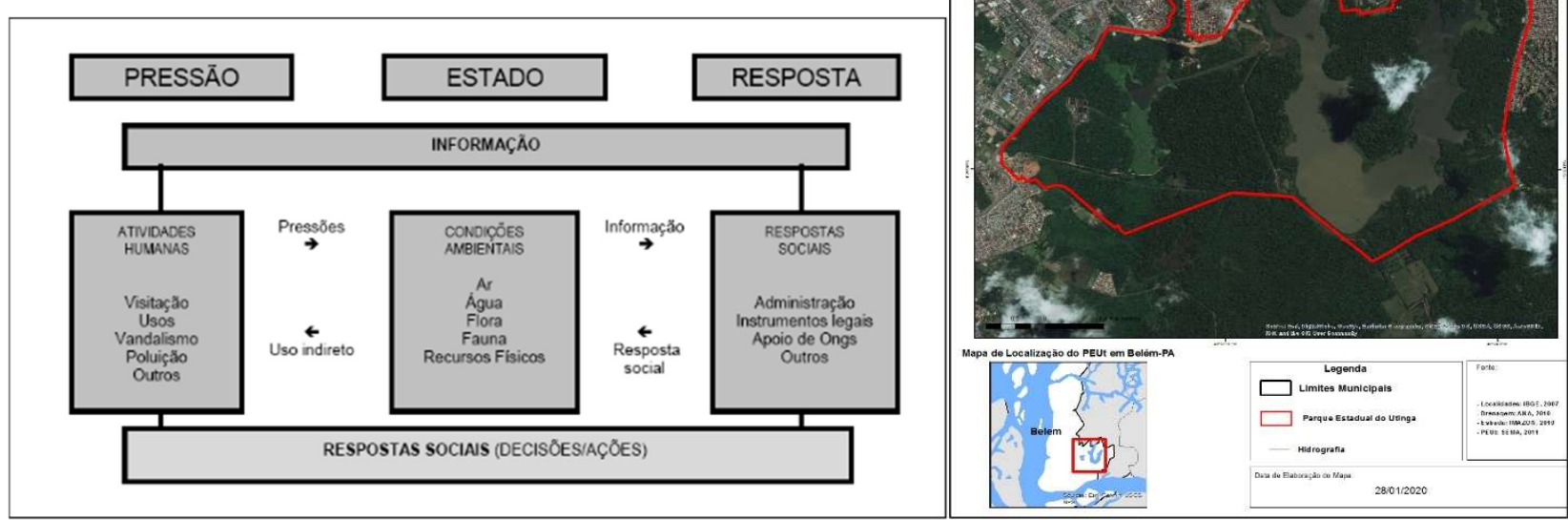

Figura 1: Matriz Pressão-Estado-Resposta adaptada para os parques urbanos.

Na prática, aplicando o modelo ao caso do PEUT, as interações estabelecidas podem ser consideradas assim: as atividades humanas que exercem pressão sobre os recursos naturais (fauna e flora, água, ar, solo) e também sobre as infraestrutura, caracterizam-se por meio de visitação, trilhas ecológicas, uso da bica, vandalismo e dejeto de lixo, entre outros tipos de exposição, alterando as condições gerais da sensibilização das áreas verde; por sua vez, essas condições ambientais são impactadas pelas pressões exercidas pelas atividades humanas no interior do parque e por fatores naturais, alterando o seu estado; e, como resposta, os agentes sociais (tomadores de decisão, moradores) refutam com instrumentos legais, projetos e ações adaptativas com objetivo de mitigar as pressões e melhorar o estado do parque urbano.

Posteriormente, a partir dos resultados obtidos com esses indicadores ambientais, deve ser calculada a pontuação para cada dimensão, que refletirá os indicadores com melhor e pior desempenho. Após a pontuação, é necessário fazer uma análise espacial os dados, sendo esta a melhor forma de evidenciar como os indicadores variam sobre a área. Para Prescott-Allen (2006) o mapeamento dos indicadores é fundamental para facilitar a comparação das áreas, vincula a avaliação com a realidade, a coleta de dados de todo o parque urbano, facilita a visualização e a análise dos bancos de dados obtidos. 
Por último é preciso fazer uma revisão dos resultados. Neste estágio busca-se um exame detalhado das ligações entre os indicadores, os padrões de desempenho, os pontos fracos e fortes, os fatores causais, as oportunidades e os obstáculos envolvidos na avaliação (VAN BELLEN, 2006). Para construir os alvos das dimensões territorial e ambientais, e assim analisar e aplicar o modelo de avaliação proposto na Unidade de Conservação, serão utilizados dados primários e secundários. Todas as fontes de dados e os critérios adotados para a análise do PEUT, bem como para construção da matriz dos alvos para a avaliação, serão descritos na avaliação final.

\section{DISCUSSÃO TEÓRICA}

A avaliação de vulnerabilidade ambiental é resultado do cruzamento do mapeamento dos indicadores ambientais com o diagnóstico do PER. Por meio dessa técnica é possível obter uma análise integrada das variáveis do meio físico e humano, permitindo apontar às áreas susceptíveis a exposição de riscos, subsidiando a avaliação da capacidade adaptativa e o controle do avanço demográfico sobre as áreas verdes.

Araújo Junior (2015), por exemplo, mostra a partir de indicadores da qualidade da água os impactos do uso do solo nas proximidades do lago Bolonha. De acordo com o autor o espelho d'água do lago Bolonha vem sendo tomado por um tipo de vegetação que recebe o nome de macrófita, a espécie encontrada no lago é predominantemente de aguapés (Eichhornia crassipes Solms) e seu surgimento estar ligado tanto a própria dinâmica do meio físico ou quanto ao aporte de nutrientes em razão da ocupação 'desordenada' as margens do lago, ou as duas atuando conjuntamente.

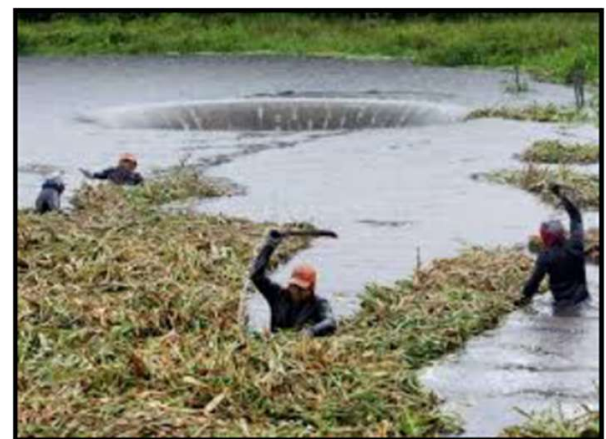

Foto 1: Retirada das macrófitas do Lago Bolonha em 2011.

Para o autor, a ocupação residencial da bacia hidrográfica do Murutucum, inserida no lago Bolonha, é responsável pela aceleração dos processos de sedimentação devido a retirada de cobertura vegetal potencializando processos de run-off, bem como à proliferação de macrófitas fixas e flutuantes no manancial devido o despejo de substâncias, as quais possam alimentar o sistema, contribuindo para aceleração de posteriores processos de eutrofização artificial.

Apesar do lago Água Preta exercer uma função removedora de cor e sedimentos mais grossos (decantação natural) estes poderão ressurgir a ser novamente acentuados por influência da decomposição de matéria vegetal no lago Bolonha. O acentuamento da cor está associado também ao tamanho do lago, que é menor, tendo para tanto menor espaço para solubilizar substâncias, ou seja, dissolvê-las. 
Assim, a comunidade fitoplanctônica, como a das macrófitas, pode ser utilizada como um indicador de qualidade ambiental, principalmente em reservatórios e a análise da sua estrutura permite avaliar alguns efeitos decorrentes de alterações ambientais. No lago Bolonha, a proliferação intensa de macrófitas pode estar evidenciando o processo de eutrofização artificial, comprometendo o abastecimento hídrico, uma vez que a qualidade da água pode ser afetada pelo aporte de macronutrientes como fósforo e nitrogênio e está proliferação estaria mesmo comprometendo a capacidade de absorção da água.

Nesse sentido, o autor apresenta que a proliferação exponencial destes vegetais é um indicador que existe uma aceleração no processo de eutrofização do lago Bolonha, devido a elevada produção de biomassa, induzindo o aumento do déficit de oxigênio, a formação de gás sulfídrico (H2S) e a diminuição do pH da água, com efeitos nocivos ao fitoplâncton, zooplâncton e à comunidade bentônica, representando um fator visível de poluição da água, além de afetar a navegação, a captação de água e a geração de energia.

Outra proposta de uso de indicadores ambientais aplicada no PEUT foi apresentada por Fidelis et al. (2015) e teve como objetivo identificar bio-geoindicadores aplicados ao planejamento de ecoturismo em UCs localizadas na RMB. A denominação bio-geoindicador vem da junção do termo bioindicador deriva do uso específico de indicadores bióticos (fauna e flora) para determinada finalidade com o de geoindicadores que são uma forma de diagnosticar evidencias geológicas, geomorfológicas e os processos que originam mudanças de curto prazo.

Logo, o termo bio-geoindicador é usado para classificar grupos bióticos, abióticos, humanos e sociais que possuem alguma sensibilidade para certos fatores que ocorrem no ambiente ou geralmente indicam perturbações de ações antropogênicas. Estes mostram as áreas em processo de degradação com aberturas de clareiras (naturais ou antrópicas), poluição de rios por meio da eutrofização e o manejo inadequado do solo.

Os autores afirmam que o turismo, apesar de ser benéfico em termos econômico e culturais provocaram diversos impactos negativos, no aspecto ambiental. O termo ecoturismo é traduzido como uma solução para o uso adequado de ambientes naturais, visando sua conservação. Sua prática está diretamente ligada com o deslocamento de pessoas para espaços que são delimitados e protegidos oficialmente pelo Estado. No PEUT, cabe lembrar, trata-se de uma das diretrizes do decreto de criação.

O método utilizado pelos autores foi o VPSIR como sistema de suporte à decisão, representa uma forma de análise que visa fornecer subsídios a gestão territorial; deriva do modelo PER adaptado pela Organização Europeia de Cooperação Econômica (OCDE).

Deste modo, as Vulnerabilidades são referentes as características do meio de análise; e consideradas como sendo políticas econômicas e sociais dos governos. As Pressões são os caminhos que estes elementos condutores são expressos e o modo como os ecossistemas e seus componentes são perturbados. Essas pressões afetam o Estado do ambiente, que consequentemente geram Impactos na saúde humana e nos ecossistemas, obrigando a formulação de respostas. Estas últimas dar-se-ão por meio de várias medidas de política, tais como regulamentos, informações, impostos e planos diretores municipais (FIDELIS et al., 2015).

Dentro dos resultados e discussões do trabalho a análise da vulnerabilidade versus pressão permitiu 
visualizar uma distribuição anormal para a relação no PEUT (Figura 7) devido à complexidade de variáveis associadas, resultantes principalmente do intenso antropismo do entorno. No PEUT foi possível observar que os bio-geoindicadores representados pela vulnerabilidade, são mais abrangentes, pois apresentam os fatores fauna terrestre, pesca e desmatamento. Além disso, o efeito de borda pode ocasionar alterações no meio biótico, que são decorrentes das transformações impostas ao meio físico.

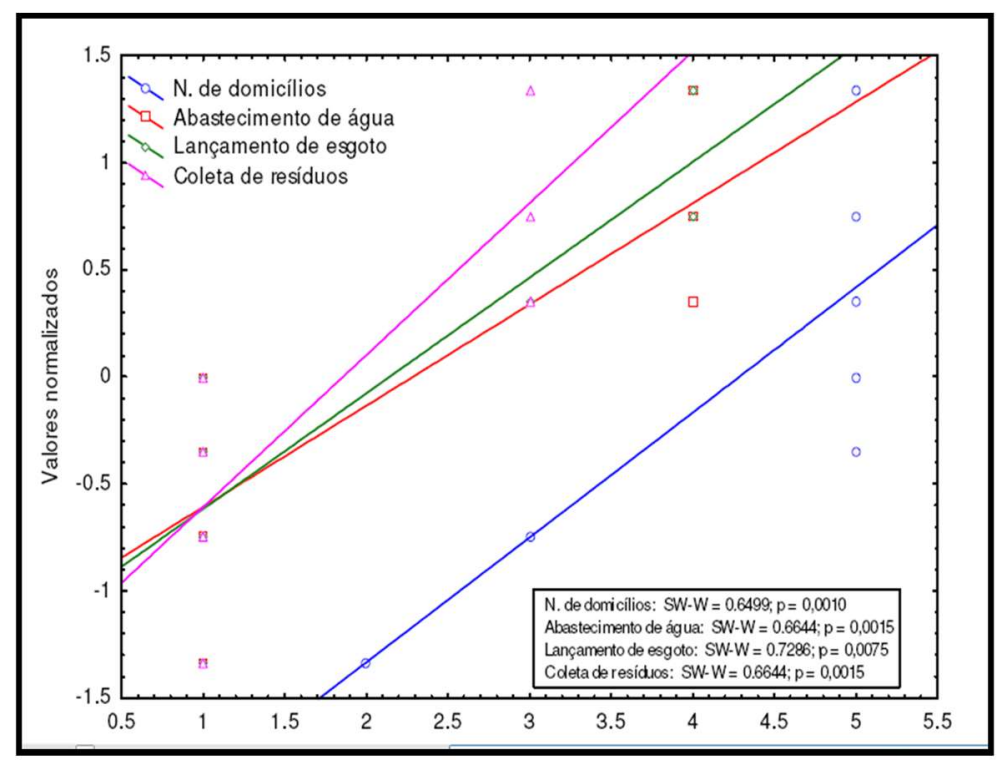

Figura 2: Teste Shapiro-Wilk aplicado a análise 'Vulnerabilidade’ x ‘Pressão' no PEUT. Fonte: Fidelis et al. (2015).

Os indicadores quando relacionados com a pressão de domicílios, demonstram níveis elevados de risco. Para os autores existe um fácil acesso da comunidade do entorno ao interior do PEUT justificado pela ineficácia da fiscalização, do elevado tamanho da UC e a falta de políticas de conscientização dos moradores do entorno. Em conclusão, o processo de ocupação do entorno como principal agravante entre as demandas de preservação do meio ambiente e as práticas de ecoturismo na área do Utinga.

Por fim Costa (2015) trabalha com a perspectiva de avaliar através de indicadores ambientais, baseado na proposta do barômetro de sustentabilidade adaptado a um modelo conceitual de PressãoEstado- Resposta (PSR) a qualidade ambiental da área do PEUT. Neste sentido, a autora realizou coleta de referentes a 3 variáveis: água, resíduos sólidos, uso e ocupação do solo, e seus respectivos indicadores ambientais.

\begin{tabular}{|c|c|c|c|}
\hline VARIÁVEL & PRESSĀO & ESTADO & RESPOSTA \\
\hline $\begin{array}{l}\text { Residuos } \\
\text { sólidos }\end{array}$ & $\begin{array}{c}\text { Residuos sólidos } \\
\text { urbanos gerados (t/dia) }\end{array}$ & $\begin{array}{l}\text { Residuos sólidos } \\
\text { manejados } \\
\text { adequadamente } \\
\text { (IRS) }\end{array}$ & Lei $12.305 / 2010$ \\
\hline Água & $\begin{array}{c}\text { Efluentes domésticos } \\
\text { (esgoto) lançados na } \\
\text { água, } \\
\text { Tipo de saneamento no } \\
\text { Bairro do Sousa }\end{array}$ & $\begin{array}{c}\text { Indice de Qualidade da } \\
\text { agua (IQA) }\end{array}$ & $\begin{array}{c}\text { Resolução } 357 / 05 / 2010 \\
\text { Lei } 11.445 / 2007 \\
\text { Companhia de Tecnologia } \\
\text { de Saneamento Ambiental } \\
\text { (CETESB) }\end{array}$ \\
\hline $\begin{array}{l}\text { Cobertura } \\
\text { vegetal e } \\
\text { uso do solo }\end{array}$ & $\begin{array}{l}\text { Taxa de desmatamento } \\
\text { anual }\end{array}$ & $\begin{array}{l}\text { Superficie remanescente } \\
\text { arbórea/área total (ha) } \\
\text { (IICV) }\end{array}$ & $\begin{array}{l}\text { Fundação do Meio } \\
\text { Ambiente (FMA). }\end{array}$ \\
\hline
\end{tabular}

Figura 3: Proposta de indicadores de PSR. Fonte: Costa (2015)

A seleção dos indicadores foi direcionada de acordo com o modelo PSR, logo foram agregados contribuindo para criação de índices que variaram de 0 a 1 com seus respectivos pesos de acordo com as 
categorias (Pressão - Estado - Resposta). Os índices foram qualificados a partir das tabelas de valoração de sustentabilidade como: ótimo, bom, regular, ruim ou crítico de acordo com o barômetro de sustentabilidade. Desta forma Costa (2015) cria um Índice de Qualidade do Meio Ambiente (IQMA) pela relação dos dados obtidos do modelo PER, adaptado a dois barômetros de sustentabilidade.

O resultado da pesquisa de Costa (2015), de acordo com os parâmetros listados pela autora, apontou um índice de resposta médio do PEUT de 52,5 considerado intermediário dentro da proposta metodológica feito pela autora para avaliar IQMA. Os indicadores de resposta de cada variável foram: produção e manejo dos resíduos sólidos $(36,0)$ efluentes domésticos $(46,0)$ cobertura vegetal e uso do solo $(82,0)$ qualidade da água $(46,0)$.

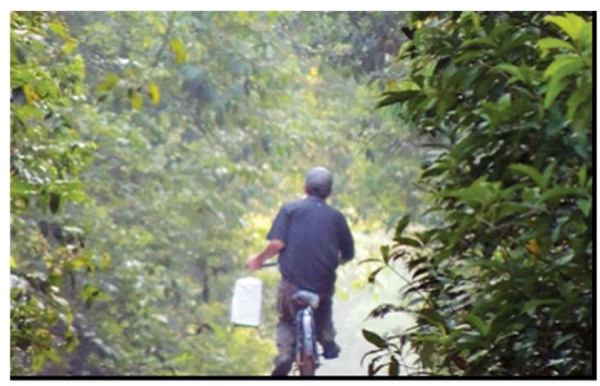

Foto 2: Morador do entorno com uma gaiola 'passarinhando' pelo PEUT.

Já a avaliação da Qualidade Ambiental do PEUT foi obtida a partir do resultado do modelo PSR adaptado a tabela de valoração qualitativa, a partir da distribuição de pesos, do Barômetro de Sustentabilidade, onde os resultados apresentados pela pressão ambiental foram $(99,5)$ e Estado $(37,3)$, porém, a partir da obtenção dessas médias foi efetuada a média aritmética obtendo o IQMA $(68,4)$. Na prática indica que as pressões exercidas no meio ambiente não estão tendo retorno satisfatório do poder público.

Em suma, Costa (2015) conclui que as leis são estabelecidas, e o poder público vem realizando fiscalizações e auditorias visando os cuidados na proteção do parque urbano, entretanto, as medidas já mencionadas são insuficientes para resolver os problemas enfrentados atualmente, uma vez que a pressão está sendo muito maior que as respostas, ou seja, o que está sendo feito pelo PEUt é pouco em relação a agressão que este parque vem sofrendo.

\section{CONCLUSÕES}

A construção de sistema de indicadores ambientais que possam ser balizadores na intervenção no espaço urbano em UCs vem se tornando preocupação crescente dos gestores urbanos e de pesquisadores. Tais instrumentos são importantes elementos na análise e avaliação de políticas públicas de sustentabilidade da cidade, bem como da gestão ambiental. Diante disso, entre as várias pesquisas realizadas no PEUt destacamos aqui três que utilizam como técnicas de investigação o uso de indicadores ambientais, embora com objetivos diferentes.

Logo, a relevância desses estudos foi a percepção de que é preciso revisar as noções simplistas de equilíbrio e de controle da biodiversidade, e entender que a realidade por trás da análise de um parque urbano, no qual a própria biodiversidade é mutável dentro de um sistema não linear que envolve a ação de 
indivíduos que afetam e são afetados pela localização, pelas características fisiográficas e por mudanças, incluindo a introdução de novas espécies, visitação ou alteração nas políticas públicas de preservação.

A partir dos resultados das pesquisas aqui citados através das técnicas e produtos de várias pesquisas desenvolvidas no PEUT o presente trabalho expõe, sucintamente, a vulnerabilidade a que os recursos ambientais da referida UC de proteção integral está sujeita devido aos processos antrópicos, seja pela ausência do cumprimento dos aspectos legais que amparam o parque urbano, além da aplicação do plano de gestão e seja pela lógica de ocupação do solo que envolva as peculiaridades das políticas públicas da região metropolitana de Belém e especial aquelas que envolve o ideário de sustentabilidade.

\section{REFERÊNCIAS}

ARAÚJO JÚNIOR, A. C.. Indicadores de qualidade ambiental no lago Bolonha, Parque Estadual do Utinga Belém do Pará. Boletim Gaúcho de Geografia, v.42, n.1, p.276-299, 2015.

COSTA, M. J. S.. Uso de indicadores ambientais na avaliação da qualidade de áreas de proteção ambiental: estudo de caso do Parque Estadual do Utinga - Belém (PA). Belém, 2015.

FIDELIS, J. F. M. A.; LIMA, S. Q.; LIMA, A. M. M.; KRAG, M. N.; GUERREIRO, Q. L. M.. Bio-geoindicadores aplicados ao ecoturismo em unidades de conservação localizadas em espaços urbanos. Revista Brasileira de Ecoturismo, São Paulo, v.8, n.2, p.212-233, 2015.

PRESCOTT-ALLEN, R.. Barometer of Sustainability: Measuring and communicatingwellbeing and sustainable development. Cambridge: IUCN, 1997.

VAN BELLEN, H. M.; JOÃO, C. G.. Avaliação de Sustentabilidade em Unidades de Conservação: Um Estudo de Caso no Parque Estadual da Serra do Tabuleiro/SC. São Paulo: ENAPG, 2016.

A CBPC - Companhia Brasileira de Produção Científica (CNPJ: 11.221.422/0001-03) detém os direitos materiais desta publicação. Os direitos referem-se à publicação do trabalho em qualquer parte do mundo, incluindo os direitos às renovações, expansões e disseminações da contribuição, bem como outros direitos subsidiários. Todos os trabalhos publicados eletronicamente poderão posteriormente ser publicados em coletâneas impressas sob coordenação da Sustenere Publishing, da Companhia Brasileira de Produção Científica e seus parceiros autorizados. Os (as) autores (as) preservam os direitos autorais, mas não têm permissão para a publicação da contribuição em outro meio, impresso ou digital, em português ou em tradução. 